\title{
How Light and Motion Bathe the Silver Screen
}

\author{
James E. Cutting \\ Cornell University
}

\begin{abstract}
Popular movies are spatiotemporal arrays of light and motion, but almost nothing is known about their distributions across whole films. Psychological research shows that the center of the screen is the most important region, but is light and motion most prominent there? I confirm that they are while exploring a sample of 160 movies released from 1935 to 2010. Concerning how light bathes the screen, I found that newer movies have greater luminance contrast than older movies; that luminance falloff can be used to estimate the average lens lengths of many movies; that screen centers are brighter than predicted by luminance falloff; and that American films noir are not actually darker than other movies of their era, but their surrounds are much darker. Concerning motion, I found that more recent movies have more motion (or change) contrast than older ones; that despite what might be predicted by camera motions, the center of the screen has the most motion; and that this is particularly striking for animated movies, which have more visual change than any other movie genre. In sum, content aside, filmmakers have crafted a viewing space for our attention and given us good reasons to look at the center of the screen.
\end{abstract}

Keywords: attention, contrast, luminance, motion, movies

"The [movie] of the future, if it is really to rise to further heights, will thus become more than any other art the domain of the psychologist who analyzes the working of the mind" Hugo Münsterberg (1915, p. $31)$.

Münsterberg was not exactly wrong, but at the time no academic psychologist followed his lead in studying film and few have done so in the intervening century. Instead it was lay psychologistsdirectors, cinematographers, and editors-who forged the new art form. Their work has been so successful that they have made movies the centerpiece of popular culture. The average person in the United States sees a bit more than five films per year on the "silver screen" (in a movie theater), and this value has remained remarkably constant over a half century. ${ }^{1}$ Yet movies began to appear on TV in 1961, on videotape in the late 1970s, on cable TV in the late 1980s, on DVDs in the mid1990s, and through Internet streaming around 2008. As a result, the British Film Institute (2012) estimated that the average adult in the United Kingdom saw 87 movies in 2011. Domestic increases in watching movies are almost certainly similar, suggesting as much as a 20 -fold increase. ${ }^{2}$

With this growth, movies now occupy our minds in ways that are new to human history. Viewers are yoked, sharing the experience such that the same brain regions are activated and with the same eye movement patterns generated (Hasson, Furman, Clark, Dudai, \& Davachi, 2008; Hasson, Nir, Levy, Fuhrmann, \& Malach, 2004; Mital, Smith, Hill, \& Henderson, 2011). I believe that the current structure of popular movies, and the changes it has

This article was published Online First March 31, 2014.

Correspondence concerning this article should be addressed to James E. Cutting, Department of Psychology, Uris Hall, Cornell University, Ithaca, NY 14853-7601. E-mail: james.cutting@cornell.edu undergone, offers rich source material that can provide insights into cognitive processing (see also Smith, Levin, \& Cutting, 2012).

Why are movies so engaging? Surely storytelling on film has not really gotten noticeably better over the last 50 years, if indeed its quality can be said to have changed for the better at all. To be sure, special effects in newer movies have allowed filmmakers to explore fantasy and science fiction situations heretofore unavailable to the medium. But since most movies have few, if any, special effects, this cannot account for the bulk of the increase in movie watching. Surely part of the attraction of movies is to learn about how people (actors) react to circumstances that we as viewers have not, and likely can never, directly experience (Zunshine, 2006, 2012). But another part of the reason for the hold that

\footnotetext{
${ }^{1}$ The term silver screen is short for the highly reflective, silver (more typically aluminum), lenticular (vertically ridged) projection screens used in early cinema. Münsterberg called movies "photoplays." And the movieattendance calculation is based on the number of movie theater tickets sold per year (The Numbers, 2013) and the estimated yearly population in the United States of individuals over 5 (http://www.census.gov).

${ }^{2}$ The average American spent 2.82 hours per day watching TV in 2012, up from 2.57 hours in 2003 (Bureau of Labor Statistics, 2012) and about 1.5 hours in the mid-1980s (Anderson, Lorch, Field, Collins, \& Nathan, 1986). Of course, Hollywood movies represent only a portion of all entertainment that people watch. The A. C. Nielson Company (www.nielson .com) estimates that movies comprise $24 \%$ of TV watching, yielding about 4.73 hours of movies per week. Since the average movie is about 1.9 hours in length, this is equivalent to 2.47 movies per week or, allowing for commercial time, about 90 to 100 movies watched per year. Moreover, such an estimate does not include interactions with computers, and Americans over 18 years of age now spend more time online than watching TV (eMarketer, 2013). Thus, with Internet streaming of movies to computers and other devices, the actual mean number of movies seen per year may be quite a bit higher. Given that theaters were the only venue in which to watch movies in 1960, the increase in movie watching over the last 50 years in the US may be 20 -fold or more.
} 
movies have on us, I claim, stems from the Münsterberg's anticipation of the mastery by filmmakers of presentational aspects of movies and how they hold our attention.

From psychological studies, we know that every cut demands eye movements and the reorientation of our attention (Mital et al., 2011). We know that the fluctuations of cuts and shot durations increasingly mimic our endogenous attentional patterns (Cutting, DeLong, \& Nothelfer, 2010; Gilden, 2001). We know also that contrasts of light against dark and motion against stillness capture our attention as well (see, e.g., Franconeri \& Simons, 2003; Hillstrom \& Yantis, 1994; Theeuwes, 1994; Wolfe \& Horowitz, 2004). Moreover, luminance contrast and motion are primitives in most algorithms generating saliency maps, which are used to predict eye movements and attention (, e.g., Itti \& Koch, 2001; Mital et al., 2011). We also know that people generally look at or near the center of a movie screen during a film (Smith, 2012, 2013; Tatler, 2007), that eye movements away from the center are quite synchronized across people (Goldstein, Woods, \& Peli, 2007; Hasson, Landesman et al., 2008), and that these are guided by the content selected by filmmakers (Smith, 2013).

Most pertinent to this article, Mital et al. (2011) have shown that aspects of luminance and motion contrasts are among the best predictors of gaze at the movies. What is generally unknown, however, is the general structure of the flood of light and motion in popular movies, which likely provides the larger frame for this attention and eye movement behavior. Also unknown are the existence of any changes in these distributions as they might have occurred over the last 75 years.

\section{Study 1: Whole-Movie Distributions of Light}

Previously my students and I measured the median amounts of light and motion across each of 160 popular movies released from 1935 to 2010 (Cutting, Brunick, DeLong, Iricinschi, \& Candan, 2011; Cutting, DeLong, \& Brunick, 2011). These movies were chosen because they had among the highest box-office revenues of their release year or they were among those with the largest number of raters on the Internet Movie Database (IMDb, http:// imdb.com). We demonstrated that these movies had, across this period, generally gotten darker and had generally more motion. Both changes were relatively incremental, quite linear across 75 years, and occurred across the five genres that we sampled-action films, adventure films, animations, comedies, and dramas (Cutting, Brunick et al., 2011; Cutting \& Candan, 2013).

Nevertheless, despite our previous results, any claim a role for increasing dimness of the cinematic image as supporting filmmakers' control of attention needs a tighter analysis. In particular, I need to determine the distributional information of average luminance within frames and across movies. That is, the previous claim made by my students and me can only be justified if there has been, over time, a general increase in luminance contrast. Thus, my first task was to assess the luminance distribution as it accumulates across whole movies.

\section{Method}

I selected 60 movies from our 160-film sample, 30 older and 30 newer. These included 10 movies each released in 1935, 1940, and 1945; and 10 each from 2000, 2005, and 2010. These movies are listed in the Appendix. Color movies were converted to black-andwhite by a standard procedure that preserves the luminance of images. ${ }^{3}$ Each frame of each movie was downsampled to $256 \times$ 256 pixels and converted to a jpeg file. The average number of frames per movie in our sample is about 165,000 . Thus, each movie presented a mean of roughly 10 billion pixels for analysis.

Every pixel was coded in an 8-bit jpeg format, yielding a number between 0 (black) and 255 (white). These are raw values and not gamma corrected for appearance on a screen. With an iterative computer-controlled procedure, the value of each pixel of each frame was placed in one of these 256 bins, and then accumulated within and across all frames of each movie. The number of pixels in each bin was then assessed for each movie, and then medians taken across groups of movies.

\section{Results}

The overall patterns of results for the older and newer movies are shown in the left panel of Figure 1. The ordinate plots the log-scaled frequency in each luminance bin, and the abscissa shows the linear array of the 256 bins. The dark function represents the median values for the 30 newer movies and the lighter gray function that for the 30 older movies.

Notice three differences between the curves. First, there are many more dark pixels in the frames of newer movies, shown at the right of the panel. This is undoubtedly due in part to changes in film stock, which allow rendering at much dimmer levels in the contemporary era. Second, the older movies have proportionately many more pixels in the lower midrange of the scale, in bins between about 75 and 150 . Finally and most importantly, although the number of pixels involved is not large, the newer movies have proportionately more bright pixels than older movies in the bin range from 200 to 256. Perhaps most strikingly, the distribution of pixels for the newer movies, plotted with a logarithmic ordinate, is quite linear between bins 20 and 234, indicating a negative exponential distribution. This is the kind of falloff one might expect from natural scenes.

The thick, slightly broken bars at the top of the graph indicate the bins in which comparisons reveal statistical differences between the means of both functions $(\alpha=.05$, uncorrected for multiple comparisons). The first thick black bar at the top left shows that 22 of the bins 0 through 24 show reliably more pixels per frame in the newer movies in this region $(z=3.6, p<.0002)$. These pixels correspond to $26 \%$ of the screen area. The thick gray bar in the middle represents 81 of the 86 bins between values of 75 and 160 . Here the pattern is reversed, with a reliably greater proportion of pixels per frame in the older movies in this region $(z=-8.24, p<.0001 ; 33 \%$ of the screen area). Finally, the broken black bar at the right represents 37 of the 57 bins between 200 and 256 that have again reversed finding reliably more pixels in the newer movies $(z=2.12, p<.02)$. This area covers only

\footnotetext{
${ }^{3}$ All of the newer movies were in color, but only three of the 30 older movies were. Nonetheless, the luminance distributions for these three movies did not differ from the 27 black-and-white movies. The luminancepreserving conversion to grayscale from RGB format is: Gray = $0.299^{*} \mathrm{R}+0.587^{*} \mathrm{G}+0.114^{*} \mathrm{~B}$, where $\mathrm{R}, \mathrm{G}$, and B are the three chromatic channels in the jpeg file. These values are in RGB color space, and deviate slightly from CIE color space (Commission Internationale de l'Eclairage, 1932).
} 

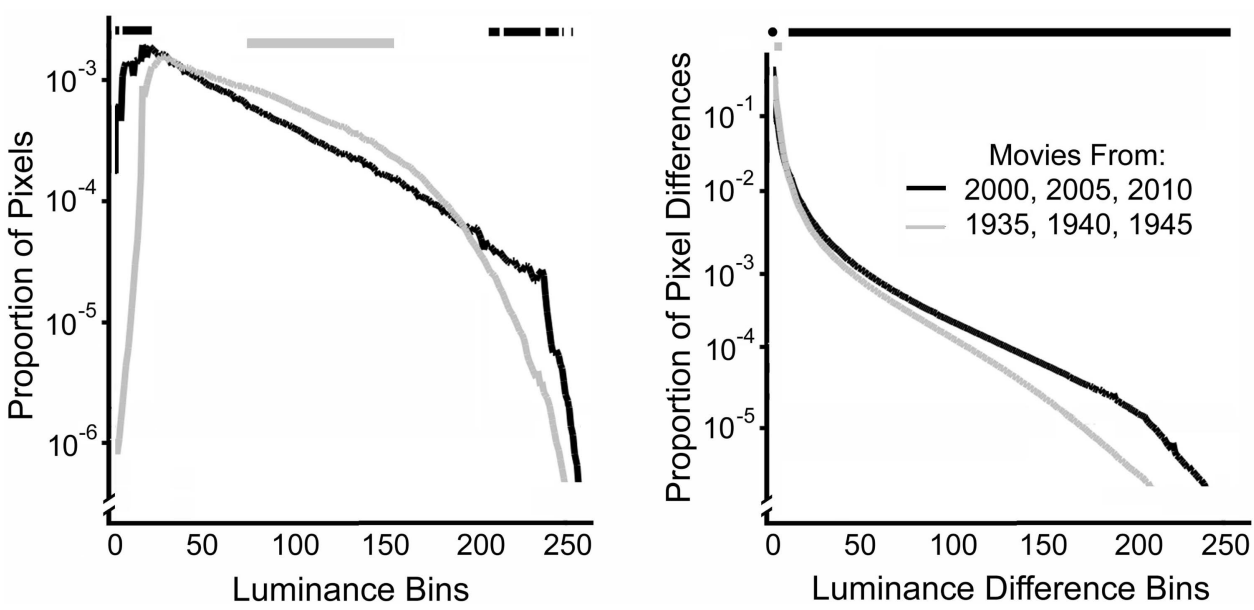

Figure 1. Luminance and motion distributions for 30 older (1935-1945, gray lines) and 30 newer (2000-2010, black lines) movies. Both ordinates are log-scaled frequencies. The top panel shows the distribution of 8-bit pixel intensities in bins from 0 to 255 , showing that newer movies have both more darker and more lighter pixels, and thus have increased contrast over the older movies. The lower panel shows the distribution differences across each pixel in frames $n$ and frames $n+2$ across the length of the movies. This measures the local change in the image (flicker) and serves as an estimate of motion. These data show that the 30 newer movies have regions of both greater and less motion than the 30 older movies, and thus have increased motion contrast.

$0.6 \%$ of the screen, but would correspond to over 2,000 pixels in a high-definition TV image. Thus, one can now conclude with considerable confidence that the luminance contrasts of the newer movies are greater, and present the viewer with both darker darks and lighter lights. Since luminance contrast attracts attention, this result provides exactly the pattern that would allow filmmakers to exercise more control over the viewers' gaze, as claimed by Smith et al. (2012). Let me turn next to a similar analysis for motion, or change, throughout these movies.

\section{Study 2: Whole-Movie Distributions of Motion}

\section{Method}

The same 60 movies were employed, 30 older and 30 newer. Motion (or change) was based on pixel differences across frames. That is, I took as an measure of motion, which we have called a visual activity index (Cutting, DeLong et al., 2011), the absolute difference in the 8-bit value at each pixel position in the images from pairs of frames, $n$ and frame $n+2$, across the entire length of each movie. ${ }^{4}$ Thus, these would represent the difference values for all $256 \times 256(65,536)$ pixels in, for example, Frames 1 and 3 to Frames 150,123 and 150,125 and beyond. An iterative computer script binned the pixel differences into the range from 0 (for no change across frames) to 255 (a change from utter black to white, or the reverse).

\section{Results}

Plots of the differences in the two classes of movies, older and newer, are shown in the right panel of Figure 1. The ordinate represents the logarithm of the frequency of difference values within image pairs, with the abscissa representing the 256 bins. Plotted are the median values across movie groups. Although the scaling makes it difficult to discern, the newer movies actually have a larger percentage of zero difference (medians of $35 \%$ vs. $25 \%$ of the screen, $t(59)=3.93 p<.0001, d=1.05)$. In contrast, the bins of absolute pixel-luminance differences between 1 and 6 ( $42 \%$ and $56 \%$ of the screen) favor the older movies (all $t \mathrm{~s}<-2.3, p \mathrm{~s}<.025, d \mathrm{~s}>2.19)$. However, every bin from an absolute difference of 12 to 243 (23\% vs. 19\% of the screen) shows reliably greater pixel differences among the newer movies (median $t>3.46, \mathrm{ps}<.0001$ ). These results mimic those for luminance contrast (left panel of Figure 1) and elaborate those of Cutting, Brunick et al. (2011): newer movies have more motion contrast than older ones. Again, such increased differences provide a stronger magnet for our attention and suggest increased filmmaker control of images (Smith, 2013).

Nonetheless, neither this result nor that for luminance shown in the left panel of Figure 1 fully addresses the issue concerning the distribution of light and motion across the movie screen. But before discussing my approach to this distributional issue, however, I need first to consider the different aspect ratios that have been used for popular movies, and the distribution of light as it passes through a lens.

\footnotetext{
${ }^{4}$ Cutting, DeLong et al. (2011) chose to look at lag-2 frame differences rather than those of lag-1 because of frequent misdigitization of older movies. That is, the transfer from movie to DVDs was not always synchronized and thus a hybridization of adjacent frames was often created (DVD frame rates are 23.97/s whereas movie rates are 24/s). Considering lag-2 correlations circumvented some of this problem. In addition, our visual activity index technically does not measure motion per se (typically called Fourier motion); instead, it measures change, and might better be called flicker (Mital et al., 2011). Nonetheless, in other work we have found this index is strongly correlated with Fourier motion and thus, we have felt that it is a reasonable surrogate.
} 
The shape of the movie screen. One of the important changes in the movies of the last 75 years concerns screen shape, which has ramifications for what is shown in film and what might be measured. We have known for quite some time that larger images engage the viewer more (see, e.g., Hatada, Sakata, \& Kusaka, 1980; Lombard, Reich, Grabe, Bracken, \& Ditton, 2000; Troscianko, Meese, \& Hinde, 2012), increasing attention, arousal, and heart rate (Reeves, Lang, Kim, \& Tatar, 1999), in part because the periphery of the visual system is more intimately connected to systems of balance (e.g., Amblard \& Carblanc, 1980). The consequence of this stimulation is to offer a stronger sense of "presence" in the viewer as being in the environment shown in the image or movie. Thus, my next pursuits are to look for differences in light and motion across various regions of the screen.

Between 1935 and the present, movies have generally appeared in one of three formats: the Academy ratio, widescreen, and CinemaScope. Such terms are used to name the approximate aspect ratio of the image projected in a movie theater. These ratios are the measure of the width of the image divided by its height. As one will see, the precision of the numbers used to represent these formats is not impressive, but in discussing the 160 movies used in this project, the great majority falls within these three categories and with a little fudging all others can be accommodated.

The Academy ratio (after the Academy of Motion Picture Arts and Sciences) is 1.37 , but often called $4: 3$, or 1.33 . This format was used exclusively in TV until the beginning of the 21 st century. It was also used exclusively in Hollywood movies from 1932 until 1953, but was rarely employed thereafter. Widescreen has an aspect ratio of 1.85 . It is also called $16: 9\left(4^{2}: 3^{2}\right.$, which is actually 1.78). This is the standard image size for modern high-definition TV sets and was introduced to movies in 1953. CinemaScope has a nominal aspect ratio of $2.35\left(4^{3}: 3^{3}\right.$, which is actually, 2.37 , but also called 2.39 or 2.40 ). In addition, the original CinemaScope movies from the mid-1950s have an aspect ratio of 2.55, a format is sometimes called CinemaScope 55. Ratios of 2.35 and above are anamorphic formats, where the film camera employs a cylindrical lens element that laterally compresses the image to use the $35-\mathrm{mm}$ film frame more effectively, then the projector has an identical lens that decompresses it. The 2.35 and above formats also create perspective distortions at the extreme edges of the image. For example, the head of a character at the edge of the screen will appear laterally elongated. Leonardo da Vinci commented on this type of distortion in linear perspective drawings five centuries ago (Richter, 1883; see also Kubovy, 1986; Pirenne, 1970).

A comparison among the three aspect ratios-1.37, 1.85, and 2.35-as they frame the movie image is shown in Figure 2. I will define three regions of interest-the center of the image, whose diameter I constrain to be $50 \%$ of the image height; the surround, or the area around the center within the Academy ratio; and the periphery, those lateral regions beyond the bounds of the 1.37 format.

Lenses and luminance falloff. Photographic images of all kinds are not uniformly bright. Instead, superimposed on whatever content there might be, image brightness follows a center-out gradient, declining as one moves from the center of the image to its edge. This phenomenon can be called dioptric luminance falloff and is illustrated in Figure 3b. The physical cause of this gradient is that less light can enter a camera lens from the periphery of the field of view than from the center (Kerr, 2007), and this relative

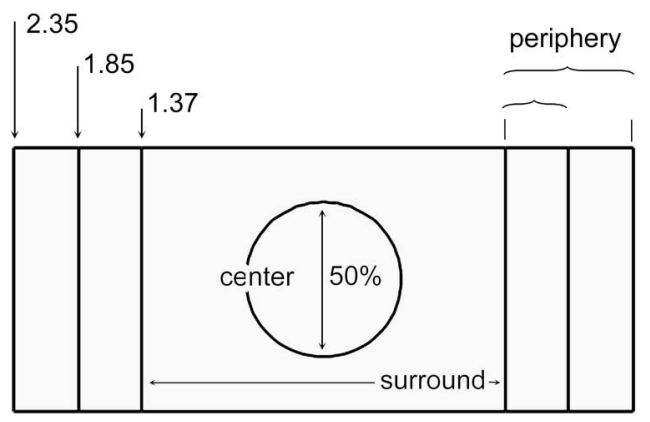

Figure 2. A schematic diagram of movie screens divided into three regions according to three prevailing aspect ratios (the measure of the width divided by the height) used in popular movies between 1935 and 2010. Among these formats, the Academy ratio is 1.37 , the widescreen ratio is 1.85 , and the CinemaScope ratio is 2.35 .

falloff can be quite significant. In the extreme this effect is called vignetting, after a style of 19th century photography in which the corners of portraits were darkened (see, e.g., London, Upton, Stone, Kobré, \& Brill, 2013; Swedlund, 1984).

Figure 3 a shows the light gathering angles for various lenses, calibrated with respect to a $35-\mathrm{mm}$ camera. It follows from Figures $3 \mathrm{a}$ and $3 \mathrm{c}$ that the margins of an image will be relatively brighter the longer the lens that is used to generate that image. Telephoto lenses are called long lenses (they literally stick out from the camera) and they have a narrower light-gathering angle. The longest lens shown in Figure $3 \mathrm{a}$ is $300 \mathrm{~mm}$. Wide-angle lenses are called short lenses, and the shortest here is $17 \mathrm{~mm}$.

For 35-mm film, a 50-mm lens is the "standard" or "normal" lens. It is called this because it renders perspective, depth, and layout in a manner closest to those projected from the environment that was photographed. Longer lenses compress depth and shorter ones expand it (Cutting, 1987, 1988; London et al., 2013). The field of view across a 50- mm lens is about $47^{\circ}$. A simple way to explain why this lens is standard in the movie context is to consider the THX certification guidelines for movie theater construction. Again, THX demands that no seat in the theater should have a view of the screen less than $36^{\circ}$ in width. This will generally mean that a seat in the middle of the theater will have a view of the screen that is about $47^{\circ}$. Because $47^{\circ}$ matches the width of an image derived from a $50-\mathrm{mm}$ lens, it is regarded as normal. That is, if the image was shot with a lens with the same cone of light as the projector dispenses, then the optics of the three-dimensional world ought to be well preserved for a seat in the middle of the theater. It will also be the best average fit for all other seats.

\section{Study 3: Distributions of Light Across Different Regions of the Movie Image}

\section{Method}

All 160 movies were used and sampled by area in keeping with their original aspect ratio. The Academy ratio (1.37) was used for 40 movies in our 160-film sample (Cutting, Brunick, et al., 2010, 2011) - 10 each from 1935, 1940, 1945, and 1950. Widescreen (1.85) was used by 44 movies, and CinemaScope (2.35) was used 

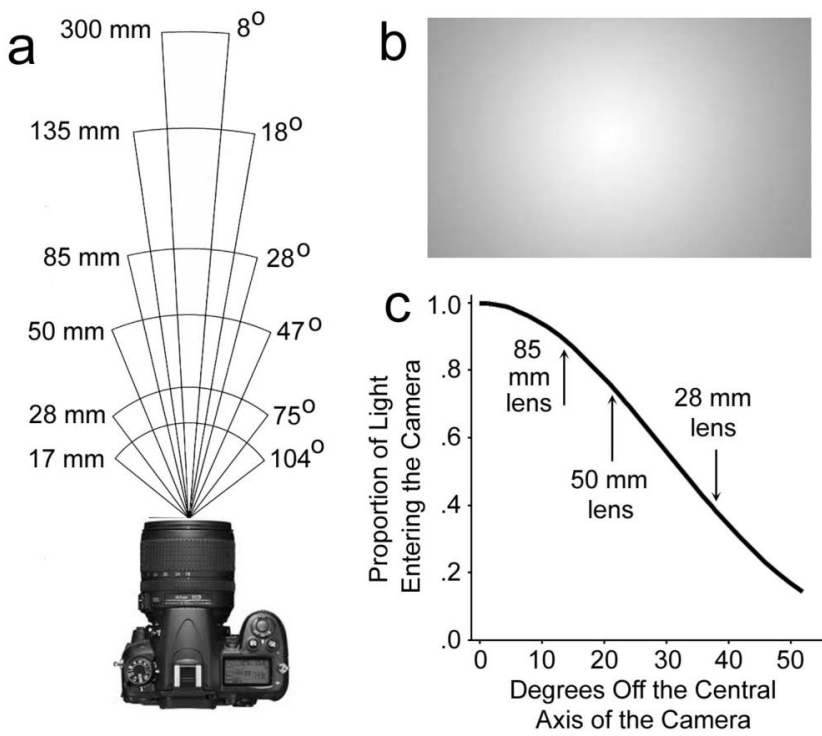

Figure 3. Panel $a$ shows the light-gathering cones for six lenses of different lengths used for 35 -mm film. Panel $b$ shows the idealized luminance falloff, and Panel $c$ shows the "cosine fourth" law $\left(\cos \alpha^{4}\right)$ that governs this falloff (Kerr, 2007). Arrows note the edges of the image frames, and hence where the falloff ends for uncropped images taken with three different lenses.

by 53, with six more using CinemaScope 55 (2.55). To be complete, however I note that four other aspect ratios were used for other movies sampled in this project-1.5 (one movie), 1.66 (10 movies), 1.75 (two movies), and 2.2 (four movies, and the standard for those shot on 70-mm film). For simplicity's sake, I will lump the first three of these alternative formats with the 1.85 movies, and the latter with the 2.35 movies. This yields roughly equal-sized sets for the three generalized formats-40 movies at the Academy ratio (1.37), 57 at widescreen $(\sim 1.85)$, and 63 for CinemaScope $(\sim 2.35)$.

Initial pixel values were retained (8-bit with a range from 0 to 255 ) and accumulated over all frames of each movie, as they were in Studies 1 and 2. To gain an appreciation for the results of the accumulated luminances of movies, consider the panels of Figure 4. The top panels show representations of the composite means for two movies-Pinocchio (Disney et al., 1940), a cel-animated movie in 1.37 format; and Harry Potter and the Deathly Hallows, Part 1 (Wigram \& Yates, 2010), an adventure movie in 2.35 format. Pinocchio is a movie of average brightness $(M=124$ on the 0-to-255 scale), and this second-to-last Harry Potter movie is the darkest in our 160-movie sample ( $M=72$; Cutting, Brunick et al., 2011). The composite luminance images are smoothly changing, boosted in luminance in the figure so that trends might be detected, and subtly mimicking the effects shown in Figure 3b. But three alterations are necessary to show the image gradients more clearly, and these are shown in the middle panels of Figure 4.

The first alteration in both panels is that a vertical slice at the extreme right of both images has been flipped. That is, within this region the pixels that were at the top are now at the bottom and those at the bottom are now at the top. Arrows mark the boundaries of this region for the two movies. The results of this manipulation corroborate the fact that for almost all natural and near-natural images luminance is darker at the bottom than at the top. Unsurprisingly, almost all photographs are taken with the lens axis parallel to the ground plane (Goodman, 1976) and almost all exterior ground surfaces and interior floors are darker than skies and ceilings.

The second alteration is that the square regions at the middles of the composite images have been switched out and placed at the top centers, and the regions at the top centers moved to the middles. This exchange shows that, despite the slight gradient from the bottom to the top of the image, the center of the composite image is brighter than the top center. Finally, the two vertical rectangles have also been swapped, one from the extreme left and one from near the center. This switch shows that the centers are brighter than the peripheries.

Put together these three image alterations denote two brightness gradients that pervade most movies. First, there is the gradient from a darker bottom to a lighter top, and all movies in our sample except for TRON: Legacy (Kushner \& Kosinski, 2010) demonstrated this gradient. Second there is the gradient from a lighter center of the image outward, as shown in Figure 3b. Indeed, 135 of the 160 movies $(84 \%, z=8.61)$ had a cumulatively brighter

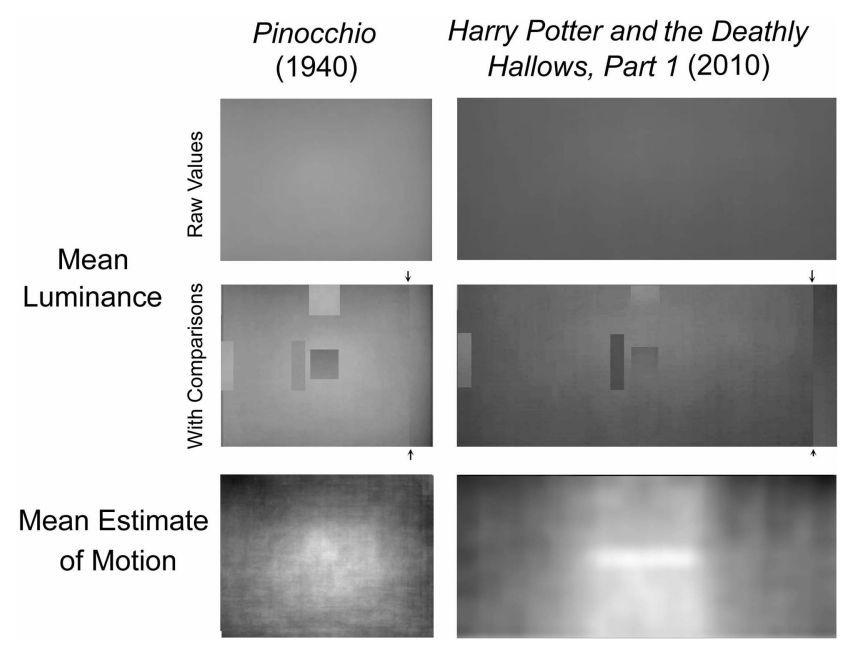

Figure 4. Composite figures representing grayscale overlays of every frame in two movies. The top panels represent the raw mean luminances. The middle panels have three alterations to show the changes across the gradients. The strip at the right of the arrows is flipped top-to-bottom to show a vertical luminance gradient; the squares and the vertical rectangles are swapped to demonstrate a gradient from the center outward. The bottom panels also show frame overlays of the same movies, but based on the absolute difference between pixels separated by two frames in each image position as they accumulated across the movies. These can be taken as estimates of the distributions of motion and change, where brightness indicates more motion in the image. Important note: Panels were independently adjusted in contrast so that the gradients and distributions can be seen well. The median gamma-corrected 8-bit values of luminance for the center and surround (see Figure 2) of Pinocchio are 153.54 and 129.68, and those for the center, surround, and periphery of the Harry Potter movie are 79.04, 74.84, and 67.32. The corresponding regional visual activities are 0.294 and .0125 for Pinocchio and $.041, .028$, and .025 for Harry Potter Thus, in terms of both luminance contrast and motion contrast the differences in Pinocchio are much greater. 
center than surround, and 108 of the 120 movies $(90 \%, z=8.67$ ) with aspect ratios greater than 1.37 had brighter cumulative centers than peripheries. Since these two gradients appear to be additive, and since I am interested only in the lateral differences across the screen, I will not consider the vertical gradient again.

With vignetting, the darkening of the edges of a photographic image (Figure $3 b$ ), the rate luminance falloff follows the fourth power of the cosine of the angle away from the principle ray of the lens (the line directly out from its center; $\cos \alpha^{4}$; Kerr, 2007). This falloff function is shown in Figure 3c. Is there a relation between luminance falloff and distribution of brightness across the sectors of movie image?

For this analysis I used the gamma-corrected 8-bit values from the jpeg files of each movie frame. That is, unlike the analyses for Figure 1 and displays of Figure 4, 1 have gamma expanded the stored values according to the formula:

$$
\text { image pixel value }=\left[(A * \text { stored pixel value })^{\wedge}(1 / \gamma)\right] / A \text {, }
$$

where $A=1 / 255$. This value first compresses the pixel values to a range between 0.0 and 1.0, then the equation adjusts them by a value inverse to the exponent gamma $(\gamma=2.2$, a standard correction value), and then decompresses them to the original range. The gamma expansion in the formula above creates an array of image values that approximate an interval scale of brightness for the human visual system where that scale ranges from 0 to 255 . In this manner, after expansion the psychological difference between image values of 40 and 60 is roughly equal to that between 180 and 200 (Poynton, 1993).

\section{Results and Discussion}

Luminance in the center, surround, and periphery. As outlined in Figure 2, I measured the luminance of the center and surround for all movies, and for the periphery of the 120 movies with aspect ratios greater than 1.37. Mean results are shown in Figure 5 and grouped in a hybrid manner. First, I separated from the others the movies from 1935 and 1940, all in 1.37 format. Second, I separated the movies from 1945 to 1955 and divided them into two categories-film noir and those that are not film noir (non-noirs). Most of these movies are in 1.37 format, but those from 1955 are in wider-screen formats. Third, I took all movies from 1955 through 2010 and grouped them into the generalized 1.85 and 2.35 formats.

All values were normalized so that centers for each movie had a value of 1.0. Thus, luminance calculations for the centers are not shown in Figure 5. Normalized values for the surrounds are shown as icons that mimic the aspect ratios of their respective movies and placed along the abscissa by the median eccentricity of the pixels within their regions. Values for the peripheries are shown in a similar manner. The dark curved lines represent the luminance falloff of various lenses if they had been chosen to project a movie on a screen whose width was $47^{\circ}$. Notice three results and relations in Figure 5.

Film noir. First and perhaps most interesting, six movies in this sample (four in 1.37 format) are classified as film noir by the IMDb-three from 1945, one from 1950, and two from 1955. Film noir is often characterized as emphasizing low-key lighting (which

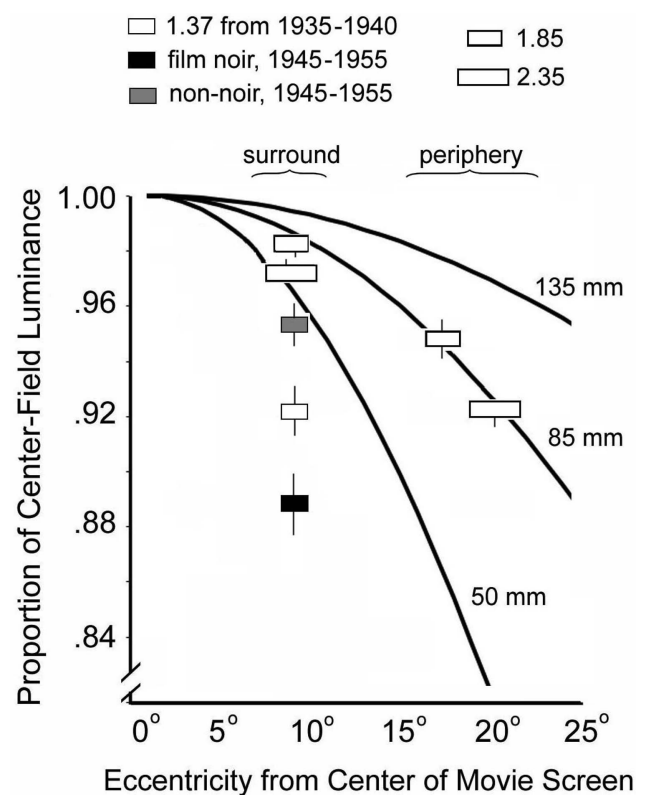

Figure 5. The mean measured luminance ratios for the image regions shown in Figure 2 for movies with different formats and from different eras. The mean surround and periphery luminance data for each movie were divided by their center luminance data. Data are shown for five categories of movie: (a) 1.37 format movies from 1935-1940, (b) six American film noir from 1945-1955, (c) 24 comparison, non-noir films from the same era, (d) all movies with 1.85 aspect ratios, and (e) all movies with 2.35 ratios. The data are superimposed on the falloff functions for lenses of different lengths. Whiskers represent one standard error of the means.

creates higher contrast between light and dark) and unbalanced compositions (Ballinger \& Graydon, 2007). Indeed, the spread of light across the screen for these movies is quite different than the 24 other movies released in the same period, $t(8.2)=4.05, p<$ $.004, d=2.82$. The relative brightness of the film noir surrounds is only $88.7 \%$ that of their centers, whereas the other movies released from 1945 through 1955 have surrounds that are 95\% as bright. Collapsed across the whole screen, however, our sample of American films noir is not reliably darker overall than other movies released in this era $(128.3$ vs. 133.2, $t(13.2)=1.58, p>$ .13).

The darker surrounds reflect the unique visual character of film noir. It is unlikely that the family of lens-falloff curves has much relevance to film noir since these were B-list movies, made for less money than the A-list movies (Finler, 2003) and thus necessarily used less-expensive equipment and lighting. Instead, filmmakers would have appeared to bathe the center of the filmed scenes with light, but left their surrounds in relative darkness. To a lesser degree the makers of other movies from the same era did this as well. After about 1960, however, film stock improved such that set lighting became less important than before, allowing luminance falloff to play a greater role.

Can mean lens length be derived from luminance falloff? Notice second, the values of the peripheries for movies with 1.85 and 2.35 formats. These fit rather cleanly along the falloff line for an $85-\mathrm{mm}$ lens. Why might this be? Let me assume that, minus the 
characters in the movie, the true luminance values of the world that we see in movie are more or less uniform left, center, and right. That is, without considering the camera lens, the ambient lateral luminance around the sets and locations at the time the filming took place was generally the same as that for their centers. If true, this means that, regardless of what is in the center of the image, the average luminance of the contents in the periphery of the filmed world would be identical to that of the center, averaged across all frames and shots. It would follow, then, that the luminance in the periphery of the movie image ought to have a value that reflects the falloff of the average lens used to film all shots and scenes. If this cascade of assumptions is true, then the values shown in Figure 5 suggest that the average lens in movies from 1955 to 2010 is about $85 \mathrm{~mm}$. How sensible is this conclusion?

Consider some evidence. In general, portrait photography uses lenses slightly longer than normal. Indeed an 85-mm lens and even a $135 \mathrm{~mm}$-lens are good candidates (London et al., 2013; Swedlund, 1984). The rationale for this choice is that such a lens is assumed to be more flattering in depicting a face. When individuals look toward the camera noses are not as large as, and ears stick out less than, they would with a $50 \mathrm{~mm}$ lens. Moreover, Salt (2009) found that about $40 \%$ of all shots in a sample of movies from the 1959 and 1999 are reverse angle shots (also called shot/reverse shots), with no change across time periods. Such shot sequences occur in scenes of dialog between two characters where one appears in one shot alternating and interleaved with shots of the other, and these are often medium closeups (showing the character from the chest up), closeups (from the shoulders up), and extreme closeups (only the head). If these were constructed in the same manner as "portraits" then longer lenses would be expected.

The progression of a scene is that it typically begins with an establishing shot (Bordwell \& Thompson, 2004), a wider-angle shot that includes the local environment and the characters of a given scene. This would be filmed with a shorter lens, perhaps in the range of 28 to $35 \mathrm{~mm}$. As the scene progresses the camera hones in on the characters, perhaps first with a two-shot (showing two characters), and then a series of one shots (showing one character at a time, alternating back and forth). For two-shots and particularly one-shots it would be common to use longer lenses in the range of 85 to $135 \mathrm{~mm}$. Since the median length of a scene is seven shots (Cutting, Brunick, \& Candan, 2012), there would be many more one- and two-shots than establishing shots, and the true mean lens length might well be near $85 \mathrm{~mm}$. Moreover, this is exactly the kind of lens use described by Sidney Lumet (1996) in directing his movie 12 Angry Men (Fonda \& Lumet, 1957).

The darker surround. The case of film noir was extreme is revealing a greatly diminished brightness in the surround compared to what one might expect from luminance falloff. Nonetheless, as one can see in Figure 5, the 20 movies from 1935 and 1940 have surrounds nearly as dark as those of film noir, and the 24 non-noir films from 1945 to 1955 have relatively dark surrounds as well. ${ }^{5}$

The reason for the relative darkness for these other earlier sets of movies seems similar to, but not as extreme as, that for film noir. That is, as noted above, film stock was not very sensitive and directors needed to flood the sets and locations with light that would be registered by the central region of the camera. Lighting was expensive in both time and money, and the surrounds would be felt to be less important, so they were less well lit. Film stock improved through the 1950s and later (Salt, 2009), so that overall less lighting was needed. This improvement is likely a major cause for the subsequent diminished differences between centers and surrounds.

Notice, however, that the surrounds for the 1.85 and 2.35 format movies are still dimmer than one might have predicted from the falloff and mean use of $85 \mathrm{~mm}$ lenses. What is the cause of this decrement? One possibility is that a closeup of the face of a character dominates the content of the center and faces are usually brighter than their surround. Thus, at least in part, I suggest that surrounds of more recent movies have backdrops that, when averaged across the length of a movie, create a greater contrast with the center. This result shows that filmmakers create centers that are brighter than one would predict from the luminance falloff of the lenses that they use. That they often contain faces is important, but that they are also brighter can be useful in attracting attention.

Revisiting Study 1. The results shown in Figure 5 have potential implications for the interpretation of the results of Study 1. In particular, all of the newer films analyzed in the left panel of Figure 1 have aspect ratios of 1.85 and greater, whereas all of the older films have aspect ratios of 1.37. Thus, the newer films have dark peripheries and the older ones have none. Since peripheries are generally dimmer than centers and surrounds, part of the increased luminance contrast shown in Figure 1 could be a result of luminance falloff.

To consider this possibility, I reanalyzed the newer films for the luminance values of pixels in their centers and surrounds only. Results are entirely consistent with, and even more striking than, those reported earlier. In particular, 20 of the 21 bins with luminance values of 2 through 22 were all more prevalent in the newer films (each $t(59)>2.0, p<.05$ ); all 103 of bins with luminances between 61 and 163 were more prevalent in the older films; and 32 of the 38 bins between 214 and 252 were more prevalent in the newer films.

\section{Camera Motion and Lens-Length Change}

Unlike the situation with light, there is no dioptric falloff of motion with eccentricity. Motion on the movie set and on location gets registered by the camera lens, on the film or on the digital medium, and projected to the movie screen equally well regardless of its place within the camera's field of view. ${ }^{6}$

Perceived motion for an observer in the real world comes in two basic types - that generated by moving objects in the environment and that generated by the moving observer (Gibson, 1954). For a filmgoer it is almost the same-characters and objects can move

\footnotetext{
${ }^{5}$ This result may seem to conflict with the results of the top panel of Figure 1, but it does not. The results of Figure 5 are normalized by the mean luminance value of the center of the screen, which for older movies is brighter than that for newer movies.

${ }^{6}$ One might think that the decreased luminance in the periphery of a movie would suppress the correlations that I perform on pixels across frames. However, to see why this is generally not the case, consider an array of pixel values in two frames. If I arbitrarily darkened or lightened both frames by $10 \%$ this would be like multiplying the values by a constant. This would not change the correlation. Similarly, the distortions that occur with widescreen-format edge smear would not lower correlations either. Imagine that this distortion doubles the number of pixels for each object represented. Doubling the number of paired entries in a correlation does not change its resulting value either.
} 
across the screen changing it locally, and the camera (as the filmgoer's eye) can move within or through a set or location creating global changes. Importantly, these camera gymnastics tend to introduce much more change in image pixels than do object and character motions in the filmed environment. The four general types are outlined in Figure 6.

The top left panel represents the schematic global flow of motion (a flowfield) on the screen when a camera pans to the left (a rotation around the vertical axis). The gray central circle is shown to coincide with the extent of the center of the screen shown in Figure 2. Here, the motion is essentially uniform and in the opposite direction from the pan. A similar flowfield can also be generated with a tracking shot, ${ }^{7}$ suggested in the lower left panel, where the camera moves left along an axis perpendicular to its axis of focus. For most environments, although all motion vectors will be to the right as in the pan, the different vectors in the image (corresponding to points in the environment) will be of different lengths inversely proportional to their distance from the camera.
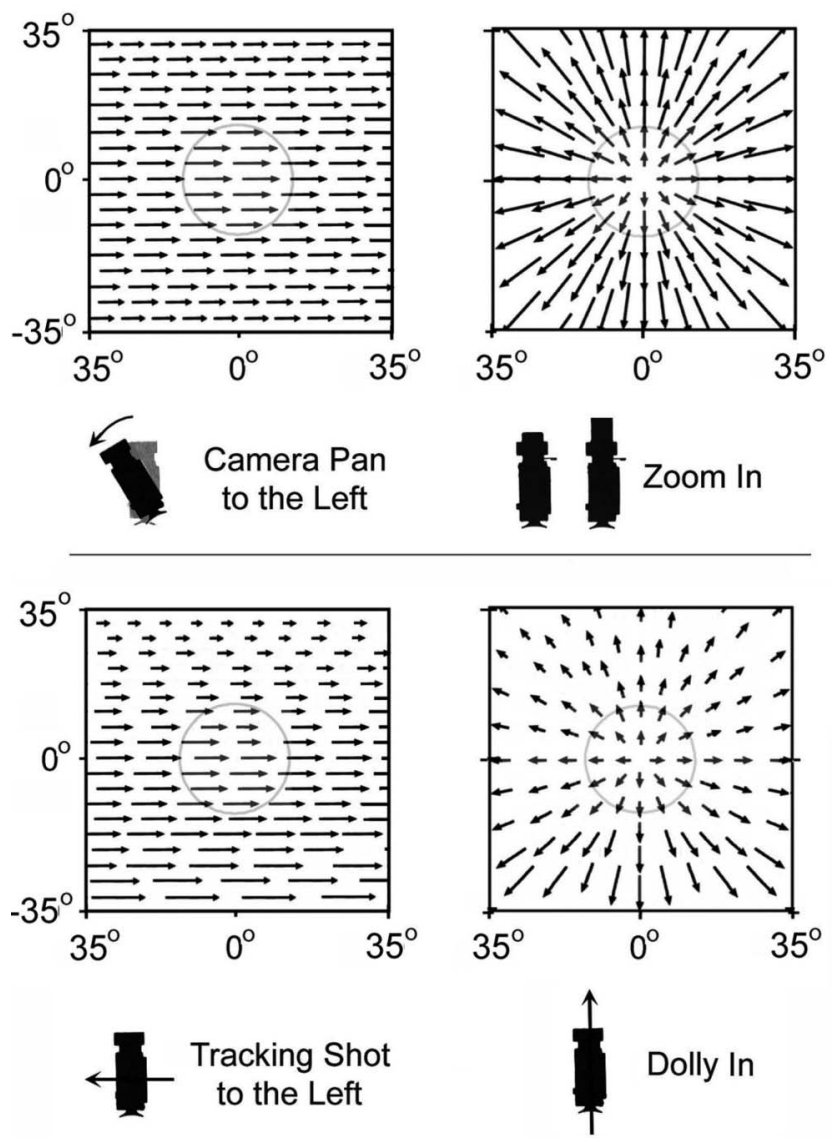

Figure 6. Schematic global motion patterns generated by four types of camera motion or change in lens length. The upper left shows a camera pan, the lower left a lateral tracking shot, the upper right a zoom in, and the lower right a dollying in. The lengths of the flow vectors (extent of motions) in upper panels are independent of the depths of objects in the environment; those in the lower panels depend greatly on object depth. The gray circle at the center of each panel corresponds to the image center, shown in Figure 2.
Vectors (and motion) associated with near objects will be greater; those associated with distant objects will be smaller. ${ }^{8}$

The top right panel represents a schematic flowfield on the screen when a camera zooms in on a character, object, or setting. That is, as the lens lengthens there will be a radial flow outward from the central axis of the lens, and the size of the vectors is proportional to their distance from the center of the image. Depth is irrelevant, as it is for the pan. However, for a dollying-in camera motion, as suggested in the lower right panel and as with the tracking shot, the length of the vectors will be inversely proportional to the distance of the object from the camera. Again, vectors (and motion) associated with near objects will be greater; those associated with distant objects will be smaller.

The depiction of these four cases is important because, if they dominated movies, they would either place motion more or less uniformly across the screen (with the pan and the tracking shot) or place greater motion in the surround and in the periphery (with the zoom in, the zoom out, the dolly in, and dolly out). None of these cases would be consistent with the notion that filmmakers place more motion at the center of the movie screen to attract the attention of viewers. Indeed, it generally follows that the more camera motion there is in a movie, the less there will be a difference in the amounts of motion spread across regions of the movie screen. Moreover, there is a suggestion that, with the evolution of smaller cameras, there has been an increasing amount of camera movement in contemporary cinema (Bordwell, 2006).

\section{Study 4: Distributions of Motion and Change Across Different Regions of the Screen}

\section{Method}

Again, the same 160 movies were used and measured for the motion (change) as in Study 2, and accumulated over the various regions of the screen as in Study 3. As examples, consider next the bottom panels of Figure 4. Notice that they have a rougher texture than the top panels for distributions of luminance. These panels show estimates of motion distributed across the screen, again for Pinocchio and Harry Potter and the Deathly Hallows, Part 1. As in Study 2, I created these images by taking the absolute difference (frame $n$ minus frame $n+2$ ) in pixel values for each location in the image, averaging those across-frame differences along the length of the movie, and then adjusting the contrast of the resulting image so that the differences within the composite could be seen. Increasing brightness in these panels indicates greater differences,

\footnotetext{
${ }^{7}$ Technically and traditionally, a tracking shot puts the camera on a track, much like a train track - temporarily laid out over an often-bumpy terrain - to create smooth motion. The machine that rides the track and that holds the camera is called a dolly. Thus, dollies and tracking shots are essentially names for the same thing. However, I, like many, have separated these two terms, suggesting that a tracking shot moves more or less orthogonally to the axis of the camera and a dolly shot moves more or less in line with the axis of the camera. Clearly there are many variants in between. In addition, with the invention of the steadicam around 1975 true tracks and dollies are often no longer needed.

${ }^{8}$ The flowfields in Figure 6 are not intended to be completely accurate representations. I have addressed the issue of flowfield accuracy in Cutting (1986, Chapter 11). Among other reasons, one needs spherical, not planar, projections to do justice to the topic.
} 
and hence an estimate of more motion or change across the film. Notice the motion is generally concentrated in the center of the screen for both movies.

\section{Results and Discussion}

Motion in the center, surround, and periphery. The left panel of Figure 7 displays the visual activity of movies by regions and by aspect ratios. Unsurprisingly, the 1.37 format movies, which date from 1935 through 1950, show considerably less motion in both their centers and surrounds than the newer movies. Cameras of that era were bulky and hard to move. Moreover, the modern focusing zoom lens was not available until the mid-1950s (Kingslake, 1989). Nonetheless, there is considerably more motion and change within the center than within the surround, $t(39)=5.9$, $p<.0001, d=4.1$. The two wider-field formats-1.85 and 2.35-are found in more recent movies, they have more motion, and they show the same trend, with more motion in the center than the surround $(t(55)=11.3$ and $t(63)=12.8, p \mathrm{~s}<.0001, d \mathrm{~s}\rangle$ 3.05). Moreover, the wider formats also have more motion in their surrounds than in their peripheries $(t(55)=11.0$ and $t(63)=12.3$, $p \mathrm{~s}<.0001, d \mathrm{~s}>2.96)$.

A modest surprise is that the peripheries of the 2.35 -format movies have more motion than those of 1.85 -format movies, $t(102.9)=17.0, p<.0001, d=3.35$ even though parts of them are farther from the center of the screen. This effect, however, clearly interacts with genre. In our sample of the 64 movies in generalized 2.35 format, 23 are action films. On the other hand, of the 56 movies in generalized 1.85 format, only five are action films. This difference-23:5::41:51-is highly reliable by a Fisher's exact test ( $p=.0005)$. Thus, the increased motion and change in movie made in CinemaScope are surely due to genre differences rather than anything else (Cutting, DeLong et al., 2011). The fact that the surrounds for 2.35 movies show slightly more motion than those for the 1.85 movies, $t(116.3)=6.7, p<.0001, d=1.24$ corroborates the difference in the peripheries, and is certainly an effect of genre as well.

The results in the left panel of Figure 7, then, imply that object motion dominates movies and that the camera motions shown in Figure 6 are either relatively minimal, or consist more of pans and tracking shots than zooms and dollies. Indeed, Salt (2006, 2009) analyzed 53 movies (1930s, 1950s, and 1990s) and 37 TV programs (1950s to 2000) and tabulated all of their shots with camera motion-pans, tilts, tracking and dolly shots, zooms, cranes, and various combinations. A tilt is a vertical rather than horizontal pan, and a crane is a vertical rather than horizontal tracking shot.

In Salt's data there are few differences between movies and TV, and not much difference across eras. Aggregating them and looking across his eight pure and combined camera motions, one finds that pure pans are the most common type of camera motion (31\%), followed by pans combined with tracking shots and dollies (29\%), pure tracking shots and dollies (18\%), combined pans and tilts $(11 \%)$, pure tilts $(6 \%)$, and pure cranes $(3 \%)$. Pure zooms are relatively rare $(2 \%)$ and are occasionally combined with pans (2\%). Combining the various pure and mixed categories in Salt's data, and considering tilts as a type of pan, pans are involved in $92 \%$ of all camera motions. Given that pans tend to create uniform flowfields across the screen, they would create a constant pedestal of motion across the screen on which to build object motion at the screen's center where it has a chance to dominate and attract the viewers' attention.

How frequent are shots with camera motions? This is not particularly easy to assess given current sources of data, but if I can assume that the movies in Salt's samples have about the same number of shots as the movies in our sample released within the same decades, I can guess at some proportions. Using both data sources, I estimate that camera motions were used in $17 \%$ of all shots from movies in the 1930s, $11 \%$ of all shots in the 1970s, and only $6 \%$ in the 1990 s. Oddly, this trend indicates that, despite the

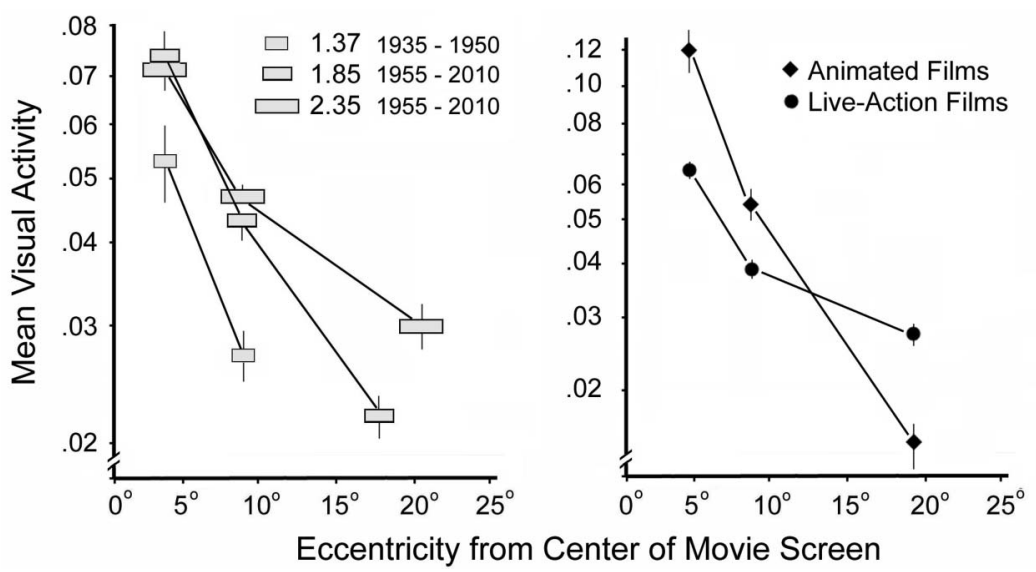

Figure 7. The left panel shows the relative amounts of motion or change for three format classes of movie in the three regions shown in Figure 2. The right panel contrasts the spatial distribution of motion in animated films with live-action films. Whiskers show one standard error of the means. The spacing on the ordinates differs, but both are derived in the same way. I took the median correlations that generated the visual activity indices and used an $r$-to- $z$ transform, which linearizes differences among near-ceiling correlations. The ordinate spacing represents these linear differences among $z$ scores rather than correlations, but values are converted back to visual activity indices. 
fact that cameras are smaller and lighter today, the camera moves less in more contemporary movies than before. In fact, however, the number of shots per movie has vastly increased over the last 80 years, and the absolute number of camera-motion shots in Salt's analysis is fairly constant across eras.

Nonetheless, the relative dearth of shots with camera motion is more good news for the distribution of motion across the screen and its effect on attention. With so few shots taken with a moving camera, the object and character motion at the center of the screen can dominate, and draw the viewer's eyes.

Animated movies. One surprise in our previous results (Cutting, DeLong et al., 2011) was that animated movies generally had more visual activity (motion) than action films. Part of this is undoubtedly a result of two facts. First, Disney cel animations ${ }^{9}$ from 1940 through the 1970s and beyond combined presentations of 24-cels and 12-cels per second within the same movie. Salt (2006, pp. 151-161) called these "ones" and "twos," for the number of times each cel would occur in the frame sequence. With "twos" the differences across frames that we measure will often be greater than one would find with "ones." Second, as suggested above, the cel-animated movies are not antialiased in the time domain. That is, there is no blurring of objects and characters when they move. These hard edges will magnify the difference in pixel values across frames, increasing our measure of visual activity. It is interesting, however, that moving from cel animations to the computer-generated animations of the mid-1990s and beyond didn't diminish the amount of visual activity; Toy Story 3 (Lasseter \& Unkrich, 2010), which is generously antialiased in the time domain, has more visual activity than The Perfect Storm (Curtiss, Henderson, Weinstein, \& Peterson, 2000), which has nearendlessly sloshing water throughout the last half of the movie.

Where is this motion in animated movies located? The composite image for Pinocchio in the upper right panel of Figure 4 provides a strong hint, and the right panel of Figure 7 provides the definitive answer. Animated movies have an impressive concentration of motion at the center of the screen. The 11 animated movies in this sample (from 1940 to 2010) have central visual activity indices of 0.122 , whereas the 149 live-action films have indices of only $0.065, t(10.7)=4.18, p<.002, d=2.55$. Moreover, the same direction of difference is found in the surround $(0.055$ vs. $0.039, t(12)=2.78, p<.02, d=1.6)$. However, the amounts of motion in the two classes of movies reverse in the periphery. The nine remaining animations have less motion (0.014) than the 111 remaining live-action films (0.027; $t(11.6)=-2.7, p<.02, d=1.58)$.

Why might this be the case? Animation has always been expensive, in drafting time during the cel era and in computing and rendering time in the digital era. That is, every square inch of a cel needs to be painted, cels for wider aspect ratios are necessarily larger than narrower ones, and painting takes time. Similarly, every pixel corresponds to a three-dimensional environment that must be rendered, wider screens have more pixels, forcing more computing time. With a moving camera in live action, on the other hand, that motion comes for free. That is, following the characters generally at the middle of the screen incurs no extra costs for capturing the motion in the surround and periphery.

Evidence in support of the extra cost of animating the wide screen comes from the release formats of the seven contemporary (1995-2010) animated movies in our sample. Six are in 1.85 format and one in 1.66 format, which following my procedure above I will place within the generalized 1.85-format group. After the categorization of these movies by IMDb as animations, the next categorization of six of the seven is as adventure films; one is next categorized as a comedy. Thus, consider a comparison of these animated movies with the live-action adventures and comedies. Within the same period, there are seven live-action adventure films and 10 comedies in our sample. One adventure film and one comedy among these had substantial computer-generated content and both appeared in 1.85 format. Of the remaining 15 movies, 11 appeared in 2.35 format. This difference-seven animated adventures and comedies in widescreen format, none in CinemaScope format, four live-action films in widescreen format, 11 in CinemaScope format—is highly reliable by a Fisher's exact test $(7: 0:: 4: 11$, $p=.0039)$. This clear difference in format choice by filmmakers suggests the avoidance of extra cost in animated filmmaking, and provides corroborative evidence for why motion is diminished in both their peripheries.

Revisiting Study 2. As before, the results shown in left panel of Figure 7 have potential implications for the interpretation of the results of Study 2. Again, all of the newer films analyzed in the right panel of Figure 1 have aspect ratios of 1.85 and greater, but the older films all have aspect ratios of 1.37. And again, since peripheries generally have less motion than centers and surrounds, part of the increased motion contrast shown in Figure 1 could be explained in this manner.

To consider this possibility, I also reanalyzed the newer films for motion values in their centers and surrounds only. Again, results are consistent with those of the earlier study. In particular, the bin with pixel-difference values of 0 was more prevalent in the newer films, $t(29)=7.7, p<.001$; all 86 of the bins with pixel-difference values between 1 and 86 were more prevalent in the older films; and 47 of the 49 bins with differences between 177 and 225 were more prevalent in the newer films.

\section{Summary and Conclusion}

The empirical analyses offered here presented seven new results concerning the spatiotemporal distributions of light and motion across 75 years of Hollywood movies. Two concern whole-movie, whole-screen analyses. First, contemporary movies offer images with greater contrast than those of an earlier era. Shoring up our previous speculations (Cutting, DeLong et al., 2011; Cutting \& Candan, 2013), this suggests that filmmakers, with the help of technological change, are exercising greater control over where the filmgoer looks (Smith, 2013; Smith et al., 2012). Second, amplifying a result from Cutting, DeLong et al. (2011), contemporary movies exploit a larger range of motion and motion contrast than do older movies. This too should contribute to filmmaker control.

The next three new results concern the general distribution of light and motion across sections of the screen. I used luminance falloff of lenses and comparisons between the centers and peripheries of movies, to estimate the mean lens length used. In general

\footnotetext{
${ }^{9}$ Cels are plastic (originally celluloid) sheets that were painted upon by master animators (who created key frames) and their assistants (who created the in-betweens). Once a sequence of sheets (frames) was assembled, they were then filmed from an animation stand (Thomas \& Johnson, 1981).
} 
the data suggest that an $85-\mathrm{mm}$ lens is about the average for most movies released since 1955 . Other sources in photography and filmmaking generally corroborate this estimate. Next, I showed that the central regions of screen space are brighter than the surrounds predicted on the basis of luminance falloff, again aiding in the filmmakers' task of having us focus on the center of the screen. And finally, despite the fact that camera motions would detract from a prominence of motion in the center of the image, motion is nonetheless greatest in the center and provides another source of information for filmmakers to hold our attention there.

The last pair of new results concerns particular genres of filmAmerican film noir and animations. Perhaps surprisingly, films noir are actually not darker than the other movies of the same era. Instead, their surrounds are significantly darker than their centers as compared to a set of movies released in the same years. This, I contend, contributes a particular look to their special quality and, of course, also falls into the hands of a controlling filmmaker. In addition, animated movies have a nonstandard distribution of motion and change. They have the greatest amount of central motion in movies, a result that has been true for 75 years, but the amount of this motion tapers off much more rapidly than for live-action films as one moves through the surround and into the periphery. The reason for this likely lies in economics. The cost of time and money to generate motion in the surround and the periphery, regardless of whether the film is cel animation or computer-generated animation, is high. Thus, these movies almost never appear in the widest formats.

In conclusion, it should be no surprise that popular movies are crafted to grab and hold our attention. How they do this has not been particularly clear beyond general appeals to the star power, narrative content, and perhaps special effects. The general goal of this set of empirical studies, and for the previous work that my students and I have published on the physical structure of movies, is to show that low-level psychophysically relevant features likely play a nontrivial role in our movie-watching behavior (see also Mital et al., 2011; Smith, 2013; Smith \& Henderson, 2008; Smith et al., 2012). Moreover, movies are arguably the most popular and economically influential art form of the last century, and they have a growing grip on global culture. To be sure, this growth partly reflects increases in leisure time, but I contend it may also reflect that storytelling in movies has evolved to match what our minds seek. As psychologists and cognitive scientists we need to understand why this might be the case. Popular film is a prime research venue for a better understanding of our perceptual systems and minds.

\section{References}

Amblard, B., \& Carblanc, A. (1980). The role of foveal and peripheral information in maintenance of postural equilibrium in man. Perceptual and Motor Skills, 51, 903-912. doi:10.2466/pms.1980.51.3.903

Anderson, D. R., Lorch, E. P., Field, D. E., Collins, P. A., \& Nathan, J. G. (1986). Television viewing at home: Age trends in visual attention and time with TV. Child Development, 57, 1024-1033. doi:10.2307/ 1130376

Bacher, W. A. (Producer) \& Stahl, J. (Director). (1945). Leave her to heaven [Motion picture]. United States: Twentieth Century Fox Home Entertainment, DVD.

Balcon, M. (Producer) \& Hitchcock, A. (Director). (1935). The 39 steps [Motion picture]. United Kingdom: Criterion Collection, DVD.
Ballinger, A., \& Graydon, D. (2007). The rough guide to film noir. London, UK: Rough Guides.

Barron, D., Seghatchian, T. (Producers) \& Newell, M. (Director). (2005). Harry Potter and the goblet of fire [Motion picture]. United Kingdom/ United States: Warner Home Video, DVD

Benedict, H. (Producer) \& Neill, R. W. (Producer \& Director). (1945). Pursuit to Algiers [Motion picture]. United States: MPI Home Video, DVD.

Berman, P. S. (Producer) \& Sandrich, M. (Director). (1935). Top hat [Motion picture]. United States: Warner Home Video, DVD.

Blenkin, J., Cunningham, C., Walsh, F. (Producers) \& Jackson, P. (Producer \& Director). (2005). King Kong [Motion picture]. New Zealand/ United States/Germany: Universal Studios Home Entertainment, DVD.

Blomquist, A. C., Cash, J. C. (Producers) \& Mangold, J. (Director). (2005). Walk the line [Motion picture]. United States/Germany: Twentieth Century Fox Home Entertainment, DVD.

Bordwell, D. (2006). The way Hollywood tells it. Berkeley, CA: University of California Press.

Bordwell, D., \& Thompson, K. (2004). Film art: An introduction (7th ed.) Boston, MA: McGraw-Hill.

Boyter, C., Brener, R., Emmerick, T., Riedel, G. (Producers) \& Dobkin, D. (Director). (2005). Wedding crashers [Motion picture]. United States: Warner Home Video, DVD.

Brackett, C. (Producer) \& Wilder, B. (Director). (1945). The lost weekend [Motion picture]. United States: Universal Home Entertainment, DVD

British Film Institute. (2012). Statistical yearbook, 2012. Retrieved from http://www.bfi.org.uk/statisticalyearbook2012/

Bureau of Labor Statistics. (2012). American time use survey. Retrieved from http://www.bls.gov/tus/

Cagney, W. (Producer) \& Lloyd, F. (Director). (1945). Blood on the sun [Motion picture]. United States: Republic Pictures Home Video, DVD.

Caracciolo, J. M., Spelling, A., Thomas, B., Topping, J. (Producers) \& McG. (Director). (2000). Charlie's angels [Motion picture]. United States/Germany: Columbia TriStar Home Entertainment, DVD.

Chaplin, C. (Producer \& Director). (1940). The great dictator [Motion picture]. United States: Warner Home Video, DVD.

Cheng, T., Soria, M. (Producers), Darnell, E. \& McGrath, T. (Directors) (2005). Madagascar [Motion picture]. United States: DreamWorks Home Entertainment, DVD.

Commission Internationale de l'Eclairage. (1932). Proceedings. Cambridge, UK: Cambridge University Press.

Coward, N. (Producer), \& Lean, D. (Director). (1945). Brief encounter [Motion picture]. United Kingdom: MGM Home Entertainment, DVD.

Cruise, T., Wagner, P. (Producers), \& Woo, J. (Director). (2000). Mission: Impossible II [Motion picture]. United States/Germany: Paramount Home Entertainment.

Curtiss, A. B., Henderson, D., Weinstein, P. (Producers) \& Peterson, W. (Producer \& Director). (2000). The perfect storm [Motion picture] United States: Warner Home Video, DVD.

Cutting, J. E. (1986). Perception with an eye for motion. Cambridge, MA: MIT Press.

Cutting, J. E. (1987). Rigidity in cinema seen from the front row, side aisle. Journal of Experimental Psychology: Human Perception and Performance, 13, 323-334. doi:10.1037/0096-1523.13.3.323

Cutting, J. E. (1988). Affine distortions of pictorial space: Some predictions for Goldstein (1987) that La Gournerie (1859) might have made. Journal of Experimental Psychology: Human Perception and Performance, 14, 305-311. doi:10.1037/0096-1523.14.2.305

Cutting, J. E., Brunick, K. L., \& Candan, A. (2012). Perceiving event dynamics and parsing Hollywood films. Journal of Experimental Psychology: Human Perception and Performance, 38, 1476-1490. doi: 10.1037/a0027737 
Cutting, J. E., Brunick, K. L., DeLong, J. E., Iricinschi, C., \& Candan, A. (2011). Quicker, faster, darker: Changes in Hollywood film over 75 years. i-Perception, 2, 569-576. doi:10.1068/10441aap

Cutting, J. E., \& Candan, A. (2013). Movies, evolution, and mind: Fragmentation and continuity. The Evolutionary Review, 4, 25-35.

Cutting, J. E., DeLong, J. E., \& Brunick, K. L. (2011). Visual activity in Hollywood film: 1935 to 2005 and beyond. Psychology of Aesthetics, Creativity, and the Arts, 5, 115-125. doi:10.1037/a0020995

Cutting, J. E., DeLong, J. E., \& Nothelfer, C. E. (2010). Attention and the evolution of Hollywood film. Psychological Science, 21, 432-439. doi:10.1177/0956797610361679

Disney, W. (Producer), Ferguson, N., Algar, J., Armstrong, S., Beebe, Jr., F., Handley, J., . . Sharpsteen, B. (Directors) (1940). Fantasia [Motion picture]. United States: Buena Vista Home Entertainment, DVD.

Disney, W. (Producer), Ferguson, N., Hee, T., Jackson, W., Kinney, J., Luske, H., . . Sharpsteen, B. (Directors) (1940). Pinocchio [Motion picture]. United States: Walt Disney Home Entertainment, DVD.

Donner, L. S., Winter, R. (Producers) \& Singer, B. (Director). (2000). $X$-men [Motion picture]. Canada/United States: Twentieth Century Fox Home Entertainment, DVD.

eMarketer. (2013, August 1). Digital set to surpass TV in time spent with US media. Retrieved from http://www.emarketer.com/Article/DigitalSet-Surpass-TV-Time-Spent-with-US-Media/1010096

Finler, J. W. (2003). The Hollywood story (3rd ed.). New York, NY: Wallflower Press.

Fonda, H. (Producer) \& Lumet, S. (Director) (1957). 12 angry men [Motion picture]. United States: MGM/UA Home Entertainment, DVD.

Foster, L., Goldsman, A., McLeod, E., Milchan, A., Wachsberger, P. (Producers) \& Liman, D. (Director). (2005). Mr. \& Mrs. Smith. [Motion picture]. United States: Twentieth Century Fox Home Entertainment, DVD.

Franconeri, S. L., \& Simons, D. J. (2003). Moving and looming stimuli capture attention. Perception \& Psychophysics, 65, 999-1010. doi: 10.3758/BF03194829

Fromkess, L. (Producer) \& Ulmer, E. (Director). (1945). Detour [Motion picture]. United States: Image Entertainment, DVD.

Fulmer, R. (Producer) \& Dindal, M. (Director). (2005). Chicken little [Motion picture]. United States: Buena Vista Home Entertainment, DVD.

Giarraputo, J. (Producer) \& Segal, P. (Director). (2005). The longest yard [Motion picture]. United States: Sony Pictures Home Entertainment, DVD.

Gibson, J. J. (1954). The visual perception of objective motion and subjective movement. Psychological Review, 61, 304-314. doi:10.1037/ h0061885

Gilden, D. L. (2001). Cognitive emissions of 1/f noise. Psychological Review, 108, 33-56. doi:10.1037/0033-295X.108.1.33

Godfrey, W., Rosenfelt, K. (Producers), \& Slade, D. (Director). (2010). The twilight saga: Eclipse [Motion picture]. United States: Warner Home Video, DVD.

Gold, E. L., Mayes, L. R. (Producers) \& Wayans, K. (Director). (2000). Scary movie [Motion picture]. United States: Dimension Home Video, DVD.

Goldstein, R. B., Woods, R. L., \& Peli, E. (2007). Where people look when watching movies: Do all viewers look in the same place? Computers in Biology and Medicine, 37, 957-964. doi:10.1016/j.compbiomed.2006 .08 .018

Goodman, N. (1976). Languages of art: An approach to the theory of symbols. (2nd ed.). Indianapolis, IN: Hackett.

Hanks, T., Rapke, J., Starkey, S. (Producers) \& Zemeckis, R. (Producer \& Director). (2000). Cast away [Motion picture]. United States: Universal Home Video, DVD.
Hardy, J., Shamberg, C. C. (Producers), \& Soderbergh, S. (Director). (2000). Erin Brockovich [Motion picture]. United States: Sony Pictures Home Entertainment.

Hasson, U., Furman, P., Clark, D., Dudai, Y., \& Davachi, L. (2008). Enhanced intersubject correlations during movie viewing correlate with successful episodic encoding. Neuron, 57, 452-462. doi:10.1016/j .neuron.2007.12.009

Hasson, U., Landesman, O., Knappmeyer, B., Valines, I., Rubin, N., \& Heeger, D. J. (2008). Neurocinematics: The neuroscience of film. Projections: The Journal for Movies and Mind, 2, 1-26. doi:10.3167/proj .2008 .020102

Hasson, U., Nir, Y., Levy, I., Fuhrmann, G., \& Malach, R. (2004). Intersubject synchronization of cortical activity during natural vision. Science, 303, 1634-1640. doi:10.1126/science.1089506

Hatada, T., Sakata, H., \& Kusaka, H. (1980). Psychophysical analysis of the "sensation of reality" induced by a wide-field display. Journal of the Society of Motion Picture \& Television Engineers, 89, 560-569. doi: $10.5594 / \mathrm{J} 01582$

Hillstrom, A. P., \& Yantis, S. (1994). Visual motion and attentional capture. Perception \& Psychophysics, 55, 399-411. doi:10.3758/ BF03205298

Howard, R. (Producer \& Director). (2000). How the Grinch stole Christmas [Motion picture]. United States/Germany: Universal Studios Home Entertainment, DVD.

Itti, L., \& Koch, C. (2001). Computational modeling of visual attention. Nature Reviews Neuroscience, 2, 194-203. doi:10.1038/35058500

Karz, M., Rice, W. A., Rosen, J. (Producers), \& Marshall, G. (Director). (2010). Valentine's day [Motion picture]. United States: Warner Home Video.

Kerr, D. A. (2007). Derivation of the "cosine fourth" law for falloff of illuminance across a camera image. Retrieved from http://dougkerr.net/ Pumpkin/articles/Cosine_Fourth_Falloff.pdf

Kingslake, R. (1989). A history of the photographic lens. London, UK: Academic Press.

Korda, A. (Producer) \& Berger, L. (Director). (1940). The thief of Baghdad [Motion picture]. United Kingdom: MGM Home Entertainment, DVD.

Kubovy, M. (1986). The psychology of perspective and Renaissance art. Cambridge, UK: Cambridge University Press.

Kushner, D. (Producer) \& Kosinski, J. (Director). (2010). TRON: Legacy [Motion picture]. United States: Walt Disney Studios Home Entertainment, DVD.

Lasseter, J. (Producer) \& Unkrich, L. (Director). (2010) Toy story 3 [Motion picture]. United States: Walt Disney Studios Home Entertainment, DVD.

Lassiter, J., Smith, W., Zee, T. (Producers) \& Tennant, A. (Director). (2005). Hitch [Motion picture]. United States: Sony Pictures Home Entertainment, DVD.

Lebenzon, C., Tobyansen, P. M. (Producers) \& Burton, T. (Director). (2010), Alice in Wonderland [Motion picture]. United States: Walt Disney Studios Home Entertainment, DVD.

Levy, S. (Producer \& Director). (2010). Date night [Motion picture]. United States: Twentieth Century Fox Home Entertainment, DVD.

Lloyd, F. (Producer \& Director). (1935). Mutiny on the Bounty [Motion picture]. United States: Warner Home Video, DVD.

Lombard, M., Reich, R. D., Grabe, M. E., Bracken, C. C., \& Ditton, T. B. (2000). Presence and television: The role of screen size. Human Communication Research, 26, 75-98.

London, B., Upton, J., Stone, J., Kobré, K., \& Brill, B. (2013). Photography (11th ed.). New York, NY: Pearson.

Lucas, G. (Producer \& Director). (2005). Star wars: Episode III-Revenge of the Sith [Motion picture]. United States: Twentieth Century Fox Home Entertainment, DVD.

Lumet, S. (1996). Making movies. New York, NY: Vintage Books. 
Malvern, P. (Producer) \& Bradbury, R. (Director). (1935). Westward ho [Motion picture]. United States: Republic Pictures Home Video, DVD.

Mankiewicz, J. L. (Producer) \& Cukor, G. (Director). (1940). The Philadelphia story [Motion picture]. United States: Warner Home Video, DVD.

Marsden, P. (Producer), Leighton, E. \& Zondag, R. (Directors). (2000). Dinosaur [Motion picture]. United States: Buena Vista Home Entertainment, DVD.

McCarey, L. (Producer \& Director). (1945). The bells of St. Mary's [Motion picture]. United States: Artisan Entertainment, DVD.

Meyers, N. (Producer \& Director). (2000). What women want [Motion picture]. United States: Paramount Home Video.

Mital, P. K., Smith, T. J., Hill, R. L., \& Henderson, J. M. (2011). Clustering of gaze during dynamic scene viewing is predicted by motion. Cognitive Computation, 3, 5-24. doi:10.1007/s12559-010-9074-z

Münsterberg, H. (1915). Why we go to the movies. Cosmopolitan, 60, 22-31. Reprinted in T. Corrigan, P. White, \& M. Mazaj (Eds.), (2010). Critical visions in film theory (pp. 10-16). New York, NY: Bedford/St. Martin's Press.

Nolan, C. (Producer \& Director). (2010). Inception [Motion picture]. United States/United Kingdom: Warner Home Video.

Numbers, The. (2013). Box office, movies stars, and idle speculation. Retrieved from http://www.the-numbers.com/movies/

Pablos, S., Taylor, R. (Producers), Coffin, P., \& Renaud, C. (Directors). (2010). Despicable me [Motion picture]. United States: Universal Studios Home Entertainment, DVD.

Pasternak, J. (Producer) \& Sidney, G. (Director). (1945). Anchors aweigh [Motion picture]. United States: Warner Home Video, DVD.

Pirenne, M. H. (1970). Optics, painting, \& photography. Cambridge, UK: Cambridge University Press.

Poynton, C. A. (1993). "Gamma" and its disguises: The nonlinear mappings of intensity in perception, CRTs, film, and video. Journal of the Society of Motion Picture \& Television Engineers, 102, 1099-1108. doi: $10.5594 / \mathrm{J} 01651$

Reeves, B., Lang, A., Kim, E. Y., \& Tatar, D. (1999). The effects of screen size and message content on attention and arousal. Media Psychology, 1, 49-67. doi:10.1207/s1532785xmep0101_4

Reid, C. (Producer) \& Ford, J. (Director). (1935). The informer [Motion picture]. United States: Warner Home Video, DVD

Richter, J. P. (1883). The notebooks of Leonardo da Vinci. Republished in 1950. New York, NY: Dover Press.

Salt, B. (2006). Moving into pictures. London, UK: Starword.

Salt, B. (2009). Film style and history: Technology and analysis (3rd ed.) London, UK: Starword.

Selznick, D. O. (Producer) \& Brown, C. (Director). (1935). Anna Karenina [Motion picture]. United States: Warner Home Video, DVD.

Selznick, D. O. (Producer) \& Conway, J. (Director). (1935). A tale of two cities [Motion picture]. United States: Warner Home Video, DVD.

Selznick, D. O. (Producer) \& Hitchcock, A. (Director). (1940). Rebecca [Motion picture]. United States: MGM Home Entertainment, DVD.

Selznick, D. O. (Producer) \& Hitchcock, A. (Director). (1945). Spellbound [Motion picture]. United States: Twentieth Century Fox Home Entertainment, DVD.

Smith, T. J. (2012). The attentional theory of cinematic continuity. Projections, 6, 1-27.

Smith, T. J. (2013). Watching you watch movies: Using eye tracking to inform cognitive film theory. In A. Shimamura (Ed.) Psychocinematics: Exploring cognition at the movies (pp. 165-191). Oxford, UK: Oxford University Press. doi:10.1093/acprof:oso/9780199862139.003.0009

Smith, T. J., \& Henderson, J. M. (2008). Edit blindness: The relationship between attention and global change blindness in dynamic scenes. Journal of Eye Movement Research, 2, 1-17.

Smith, T. J., Levin, D. T., \& Cutting, J. E. (2012). A window on reality: Perceiving edited moving images. Current Directions in Psychological Science, 21, 107-113. doi:10.1177/0963721412437407

Spacey, K. (Producer), \& Fincher, D. (Director). (2010). The social network [Motion picture]. United States: Sony Pictures Home Entertainment.

Swedlund, C. (1984). Photography (2nd ed.). Fort Worth, TX: Harcourt, Brace, \& Jovanovich.

Tatler, B. W. (2007). The central fixation bias in scene viewing: Selecting an optimal viewing position independently of motor biases and image feature distributions. Journal of Vision, 7(14), article 4. doi:10.1167/7 .14 .4

Thalberg, I. (Producer) \& Wood, S. (Director). (1935). A night at the opera [Motion picture]. United States: Warner Home Video, DVD.

Theeuwes, J. (1994). Endogenous and exogenous control of visual selection. Perception, 23, 429-440. doi:10.1068/pp.230429

Thomas, F., \& Johnson, O. (1981). The illusion of life: Disney animation New York, NY: Abbeville Press.

Troscianko, T., Meese, T. S., \& Hinde, S. (2012). Perception while watching movies: Effects of physical screen size and scene type. i-Perception, $3,414-425$

Wald, J., Warner, J. L. (Producers), \& Curtiz, M. (Director). (1945) Mildred Pierce [Motion picture]. United States: Warner Home Video, DVD.

Wallis, H. B. (Producer), \& Curtiz, M. (Director). (1940). Santa Fe trail [Motion picture]. United States: Warner Home Video, DVD.

Wallis, D. B., Warner, J. L. (Producers) \& Curtiz, M. (Director). (1935). Captain Blood [Motion picture]. United States: Warner Home Video, DVD.

Wanger, W. (Producer) \& Hitchcock, A. (Director). (1940). Foreign correspondent [Motion Picture]. United States: Warner Home Video, DVD.

Wigram, L. (Producer) \& Yates, D. (Director). (2010) Harry Potter and the deathly hallows: Part 1 [Motion picture]. United Kingdom/United States: Warner Home Video, DVD.

Wolfe, J. M., \& Horowitz, T. S. (2004). What attributes guide the deployment of visual attention and how do they do it? Nature Reviews Neuroscience, 5, 495-501. doi:10.1038/nrn1411

Wyler, W. (Producer \& Director). (1940). The letter [Motion picture]. United States: Warner Home Video, DVD.

Zanuck, D. F. (Producer) \& Boleslawksi, R. (Director). (1935). Les misérables [Motion picture]. United States: CBS/Fox Home Video, DVD.

Zanuck, D. F. (Producer) \& Ford, J. (Director). (1940). The grapes of wrath [Motion picture]. United States: Twentieth Century Fox Home Entertainment, DVD.

Zunshine, L. (2006). Why we read fiction. Columbus, OH: The Ohio State University Press.

Zunshine, L. (2012). Getting inside your head: What cognitive science can tell us about popular culture. Baltimore, MD: Johns Hopkins University Press. 


\section{Appendix}

\section{Filmography for Studies 1 and 2}

\section{5}

Balcon \& Hitchcock (1935), The 39 Steps

Berman \& Sandrich (1935), Top Hat

Lloyd (1935), Mutiny on the Bounty

Malvern \& Bradbury (1935), Westward Ho

Reid \& Ford (1935), The Informer

Selznick \& Brown (1935), Anna Karenina

Selznick \& Conway (1935), A Tale of Two Cities

Thalberg \& Wood (1935), A Night at the Opera

Wallis, Warner, \& Curtiz (1935), Captain Blood

Zanuck \& Boleslawksi (1935), Les Misérables

\section{0}

Chaplin (1940), The Great Dictator

Disney, Ferguson, Algar et al. (1940), Fantasia

Disney, Ferguson, Hee et al. (1940), Pinocchio

Korda \& Berger (1940), The Thief of Baghdad

Mankiewicz \& Cukor (1940), The Philadelphia Story

Selznick \& Hitchcock (1940), Rebecca

Wallis \& Curtiz (1940), Santa Fe Trail

Wanger \& Hitchcock (1940), Foreign Correspondent

Wyler (1940), The Letter

Zanuck \& Ford (1940), The Grapes of Wrath

\section{5}

Bacher \& Stahl (1945), Leave Her to Heaven Benedict \& Neill (1945), Pursuit to Algiers Brackett \& Wilder (1945), The Lost Weekend Cagney \& Lloyd (1945), Blood on the Sun Coward \& Lean (1945), Brief Encounter Fromkess \& Ulmer (1945), Detour McCarey (1945), The Bells of St. Mary's Pasternak \& Sidney (1945), Anchors Aweigh Selznick \& Hitchcock (1945), Spellbound Wald, Warner, \& Curtiz (1945), Mildred Pierce

\section{0}

Caracciolo, Spelling, Thomas, Topping, \& McG (2000), Charlie's Angels

Cruise, Wagner, \& Woo (2000), Mission: Impossible II

Curtiss, Henderson, Weinstein, \& Peterson (2000), The Perfect Storm
Donner, Winter, \& Singer (2000), X-Men

Gold, Mayes, \& Wayans (2000), Scary Movie

Hanks, Rapke, Starkey, \& Zemeckis (2000), Cast Away

Hardy, Shamberg, \& Soderbergh (2000), Erin Brockovich

Howard (2000), How the Grinch Stole Christmas

Marsden, Leighton, \& Zondag (2000), Dinosaur

Meyers (2000), What Women Want

\section{5}

Barron, Seghatchian, \& Newell (2005), Harry Potter and the Goblet of Fire

Blenkin, Cunningham, Walsh, \& Jackson (2005), King Kong

Blomquist, Cash, \& Mangold (2005), Walk the Line

Boyter, Brener, Emmerick, Riedel, \& Dobkin (2005), Wedding

Crashers

Cheng, Soria, Darnell, \& McGrath (2005), Madagascar

Foster, Goldsman, McLeod, Milchan, Wachsberger, \& Liman (2005), Mr. \& Mrs. Smith.

Fulmer \& Dindal (2005), Chicken Little

Giarraputo \& Segal (2005), The Longest Yard

Lassiter, Smith, Zee, \& Tennant (2005), Hitch

Lucas (2005), Star Wars: Episode III-Revenge of the Sith

\section{0}

Godfrey, Rosenfelt, \& Slade (2010), The Twilight Saga: Eclipse Karz, Rice, Rosen, \& Marshall (2010), Valentine's Day Kushner \& Kosinski (2010), TRON: Legacy

Lasseter \& Unkrich (2010), Toy Story 3 Lebenzon, Tobyansen, \& Burton (2010), Alice in Wonderland Levy (2010), Date Night

Nolan (2010), Inception

Pablos, Taylor, Coffin, \& Renaud (2010), Despicable Me

Spacey (2010), The Social Network

Wigram \& Yates (2010), Harry Potter and the Deathly Hallows: Part 1

\section{Other Films Cited}

Fonda \& Lumet (1957), 12 Angry Men

Received July 3, 2013

Revision received December 4, 2013

Accepted January 13, 2014 